\title{
One-pot low temperature synthesis and characterization of hybrid poly(2-pyrrolidone) microparticles suitable for protein immobilization
}

\author{
Nadya Dencheva ${ }^{\text {a }}$, Joana Braz ${ }^{\text {a }}$, Teresa G. Nunes ${ }^{\mathrm{b}}$, Filipa D. Oliveira ${ }^{\mathrm{a}}$, Zlatan Denchev ${ }^{\mathrm{a},{ }^{*}}$ \\ a Institute for Polymers and Composites, University of Minho, 4800-058, Guimarães, Portugal \\ ${ }^{\mathrm{b}} \mathrm{CQE}$, Instituto Superior Técnico, Universidade de Lisboa, Av. Rovisco Pais, 1049-001, Lisboa, Portugal
}

\section{A R T I C L E I N F O}

\section{Article history:}

Received 14 March 2018

Received in revised form

26 April 2018

Accepted 29 April 2018

Available online 8 May 2018

\section{Keywords:}

Polyamide 4

2-Pyrrolidone

Anionic ring-opening polymerization

Magnetic microparticles

Protein carriers

\begin{abstract}
A B S T R A C T
Neat and hybrid poly(2-pyrrolidone), i.e. polyamide 4 (PA4) microparticles containing magnetic or conductive metal, metal oxide, or carbon nanotube fillers were prepared via environmentally-friendly solventless activated ring-opening polymerization of 2-pyrrolidone at $40^{\circ} \mathrm{C}$. The method produces high porosity microparticles with diameters of $5-12 \mu \mathrm{m}$ and conversion to PA4 of $56-65 \%$. Their structure and properties were characterized by light- and electron microscopy, thermal, spectral and Xray diffraction techniques. Two crystalline polymorphs, namely $\alpha$ - and $\beta-$ PA4, were found to coexist at room temperature by X-ray diffraction. The assessment of the adsorption capacity of the PA4 hybrid microparticles toward model protein showed up to 60\% efficiency only after $1 \mathrm{~h}$ of incubation without any preliminary activation or functionalization.
\end{abstract}

๑) 2018 Elsevier Ltd. All rights reserved.

\section{Introduction}

The synthesis of Nylon 4 or polyamide 4 (PA4) by ring-opening bulk polymerization of 2-pyrrolidone (2PD) was first patented by Ney et al., in 1953 [1], followed by some improvements disclosed by C. Barns [2]. Later theoretical studies showed that a non-activated anionic polymerization of 2PD takes place under those conditions initiated by the in-situ forming of alkali salt of 2PD, e.g., 2-oxo-1pyrrolidinyl potassium [3]. Sekigichi et al. [4] used N-acetyl lactams as activators of the anionic polymerization of 2PD and its derivatives, the anionic initiator being pre-prepared alkaline salts of lactams or such with non-metallic cation. Another activator specific for the 2PD polymerization obtained in-situ as a reaction product of 2PD-alkali salt and benzoyl chloride has been described by Kawasaki et al. [5]. Similar initiator-activator system and reaction conditions were applied more recently to synthesize high molecular weight anionic PA4 homopolymer and PA46 copolymers [6].

Soon after the first successful syntheses it was established that, because of its high amide content, PA4 demonstrates mechanical resistance, dyeability and moisture intake significantly higher than

\footnotetext{
* Corresponding author.

E-mail address: denchev@dep.uminho.pt (Z. Denchev).
}

the traditional polyamides for textile fibers. However, the dense network of intermolecular $\mathrm{H}$-bonds between the backbone amide groups results in a high melting temperature of ca. $265^{\circ} \mathrm{C}$ at which fast and intense thermal degradation starts. This impedes the normal melt processing of PA4 to filaments, whereas the solution spinning alternative has shown prohibitive costs [7]. Efforts for improving the thermal stability of PA4 have been attempted by either chemical modification of chain ends [8,9] or backbone amide groups [10], even though only marginal improvements have been reported. All this resulted in low interest toward PA4 in the form of textile fibers.

During the last decade, however, the relatively easy degradation of PA4 and its possible practical implementation have been subject of intensive research. The thermal degradation of PA4 is considered to occur by a depolymerization mechanism based on the low thermodynamic polymerizability of 2PD [11,12]. Moreover, PA4 and some of its copolymers have been reported to be biodegradable in compost soils and activated sludge, containing certain bacteria and fungi [13,14], as well as in seawater [15]. At the same time, some very recent studies indicate that the 2PD monomer can be prepared from biomass by a hybrid synthetic route involving biological and chemical processes [16].

The biodegradability of PA4 in various environments and the possibility of sustainable synthesis of the 2PD monomer could potentially result in interesting biotechnological applications thus 
reestablishing the industrial interest toward products on its basis. For this to happen, it is of prime importance to find a way to produce PA4 directly in its form of application, e.g., particles with controllable structure and morphology, without the use of melt processing or such including toxic and polluting solvents. As a step in this direction, Kim et al. [17] developed a process for PA4 microspheres prepared by activated anionic ring-opening polymerization (AAROP) of $2 \mathrm{PD}$ in a paraffin oil/2PD heterogeneous medium, in the presence of suitable surfactant. Potassium tertbutoxide and benzoyl chloride were used for in-situ preparation of the initiator/activator complex.

The present work suggests a simplified and environmentalfriendly method based on AAROP of 2PD to produce PA4 microparticles in good yields, with controlled size, shape and porosity. The polymerization occurs at mild conditions of $40^{\circ} \mathrm{C}$ and uses the proper 2PD monomer as a reaction media thus excluding any solvents or surfactants. Both neat PA4 microparticles (MP) and hybrid PA4 microparticles (HMP) carrying loads of magnetic or conductive micro- and nanofillers were synthesized. To the best of our knowledge, one-pot synthesis of hybrid PA4 microparticles with magnetic or electro conductive loads has never been reported before. The structure, morphology and the most important properties of the MP and HMP were characterized. A preliminary study on their adsorption capacity toward a model protein was also carried out.

\section{Experimental}

\subsection{Materials}

2-Pyrrolidone 99\%, (2PD) was purchased from Sigma Aldrich and used as received. As polymerization activator, Brüggolen $C 20^{\circledR}$ (C20) from Brüggemann Chemical, Germany was used. According to the manufacturer, it contains $80 \mathrm{wt} \%$ of blocked aliphatic diisocyanate in ECL (Fig. 1, C20). The initiator sodium dicaprolactamato-bis-(2-methoxyethoxo)-aluminate (80 wt \% in toluene) (Dilactamate $\left.{ }^{\circledR}, D L\right)$ was purchased from Katchem and used without further treatment (Fig. 1, DL).

The powdered $\mathrm{Fe}_{3} \mathrm{O}_{4}$ and $\mathrm{Cu}$ are products of Sigma-Aldrich with $+99 \%$ purity and grain sizes of $50-80 \mathrm{~nm}$ and $>10 \mu \mathrm{m}$, respectively. The soft, non-insulated Fe particles (99\%) with average diameters of 3-5 $\mu \mathrm{m}$ were kindly donated by the manufacturer BASF, Ludwigshafen. Two types of such Fe particles were used without and with phosphate coating. The multi-walled carbon nanotubes (CNT) were purchased from Sigma Aldrich. The acetone and methanol solvents of "puriss" grade were purchased from Sigma-Aldrich and used as received.

\subsection{Anionic ring opening polymerization to microparticles}

The polymerization was carried out in a $250 \mathrm{~mL}$ glass flask supplied with magnetic stirrer and inlet for dry nitrogen. In a typical synthesis of neat PA4 microparticles (PA4 MP), $0.2 \mathrm{~mol}$ of 2PD and $1.5 \mathrm{~mol} \%$ of $\mathrm{C} 20$ were added and stirred until the latter reagent was fully dissolved. Then, $3 \mathrm{~mol} \%$ of DL were added under nitrogen atmosphere. The temperature was gradually increased from $23^{\circ} \mathrm{C}$ to $40^{\circ} \mathrm{C}$ and the system was put under 50 mbar. Reaction times of 6 and $24 \mathrm{~h}$ (from the point of DL addition) were applied for all samples, the temperature being kept at $40^{\circ} \mathrm{C}$ under constant stirring. The PA4 MP fine powders were isolated by dissolving the reaction mixture in acetone in order to eliminate the nonpolymerized $2 \mathrm{PD}$, followed by vacuum filtration, washing several times with methanol to eliminate low molecular weight oligomers and drying the product for $1 \mathrm{~h}$ in a vacuum oven at $50^{\circ} \mathrm{C}$. All PA4 powders were then subjected to a $4 \mathrm{~h}$ Soxhlet extraction with methanol to eliminate any traces of oligomers.

In a typical synthesis of hybrid PA4 HMP, 1 wt. \% of the filler (Fewith or without phosphate coating, $\mathrm{Cu}, \mathrm{Fe}_{3} \mathrm{O}_{4}$ ), or $0.1 \mathrm{wt}$. \% of CNT was added to 2PD prior the catalytic system, under nitrogen and stirring. The rest of the polymerization and isolation procedures were performed in the same way as in the case of PA4 MP. Table 1 presents the sample designation and compositions.

\subsection{Experimental methods}

The intrinsic viscosity measurements were performed with neat PA4 particles in $97 \%$ sulfuric acid at a concentration of $0.2 \mathrm{~g} / \mathrm{dL}$ with a suspended level Ubbelohde viscometer thermostatted at $23^{\circ} \mathrm{C}$. Flow times are recorded as an average of at least 10 runs.

Bright field optical microscopy of PA4 particles' sizes, roundness, and their distributions were performed in an Olympus $\mathrm{BH}-2 \mathrm{mi}$ croscope (Japan) equipped with the Leica Application Suite 4.4 software for image processing. The scanning electron microscopy (SEM) studies were performed in a NanoSEM-200 apparatus of FEI Nova using mixed secondary electron/back-scattered electron inlens detection. The pulverulent samples were observed after sputter-coating with Au/Pd alloy in a 208 HR equipment of Cressington Scientific Instruments with high-resolution thickness control.

The differential scanning calorimetry (DSC) measurements were carried out in a $200 \mathrm{~F} 3$ equipment of Netzsch at a heating/cooling rate of $10^{\circ} \mathrm{C} / \mathrm{min}$ under nitrogen purge. The typical sample weights were in the $10-15 \mathrm{mg}$ range. The thermal stability and the real inorganic load $R L$ of all PA4 powders were established by means of thermogravimetric analysis (TGA) in a Q500 gravimetric balance (TA Instruments), heating the samples to $600^{\circ} \mathrm{C}$ at $10^{\circ} \mathrm{C} / \mathrm{min}$ in a nitrogen atmosphere. The $R L$ value of PA4 HMP was calculated according to Equation (1):

$$
R L=R_{i}-R_{P A 4}, \quad[\%]
$$

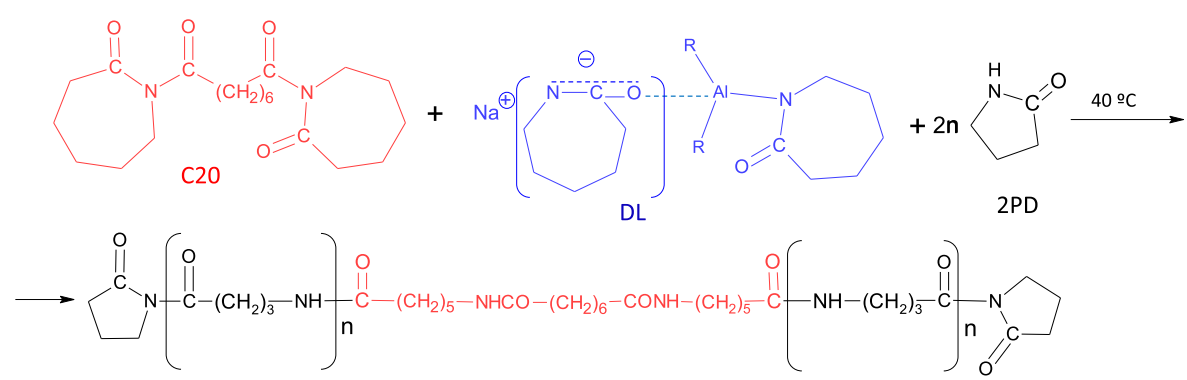

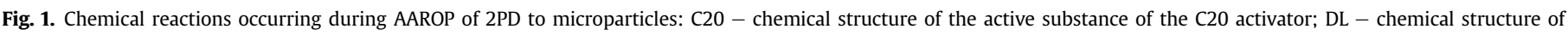
dicaprolactamato-bis-(2-methoxyethoxo)-aluminate (initiator), $\mathrm{R}=\mathrm{OCH}_{2} \mathrm{CH}_{2} \mathrm{OCH}_{3} ; 2 \mathrm{PD}=2$-pyrrolidone. 
Table 1

Designation and initial characterization of the PA4 microparticles.

\begin{tabular}{|c|c|c|c|c|c|c|}
\hline Sample & RL wt. \% & Yield wt.\% & LMWF wt. \% & {$[\eta] \mathrm{dL} / \mathrm{g}$} & Equivalent diameter $d_{\max }, \mu \mathrm{m}$ & Average roundness $d_{\max } / d_{\min }$ \\
\hline PA4-2/1 & - & 44.3 & 1.8 & $\begin{array}{l}0,822^{a} \\
0,928^{b}\end{array}$ & $\begin{array}{l}4-6 \\
10-12\end{array}$ & $1.1-1.3$ \\
\hline PA4-3/1.5 & - & 55.5 & 3.0 & $\begin{array}{l}0,802 \\
0929\end{array}$ & $8-10$ & $1.2-1.3$ \\
\hline PA4-4/2 & - & 58.7 & 3.2 & $\begin{array}{l}0,777 \\
0932\end{array}$ & $6-9$ & $1.2-1.3$ \\
\hline Fe-1 & 2.0 & 55.4 & 3.1 & - & $10-12$ & $\begin{array}{l}1.2-1.3 \\
3.5-4.0\end{array}$ \\
\hline $\mathrm{Fe}_{3} \mathrm{O}_{4}-1$ & 1.6 & 52.8 & 1.1 & - & $5-9$ & $\begin{array}{l}1.1-1.3 \\
3.2-3.3\end{array}$ \\
\hline $\mathrm{Fe}(\mathrm{C})-1$ & 1.2 & 57.5 & 1.1 & - & $10-12$ & $\begin{array}{l}1.2-1.3 \\
3.6-4.1\end{array}$ \\
\hline $\mathrm{Cu}-1$ & 2.5 & 64.6 & 1.5 & - & $8-12$ & $1.2-1.3$ \\
\hline CNT-01 & 0.3 & 60.0 & 1.1 & - & $5-8$ & $1.2-1.3$ \\
\hline
\end{tabular}

Notes.

$\mathrm{LMWF}=$ Low molecular weight fraction after $4 \mathrm{~h}$ Soxhlet extraction with methanol, wt.\%.

$\mathrm{RL}=$ real load content, \%, as calculated from TGA data according to Eq. (1).

$\mathrm{Fe}(\mathrm{C})$ - Phosphate coated Fe.

a Intrinsic viscosity after $6 \mathrm{~h}$ polymerization time.

b Intrinsic viscosity, after $24 \mathrm{~h}$ polymerization time.

and $R_{i}$ represents the carbonized residue of the respective loaded PA4 HMP measured by TGA.

The PA4 MP and HMP were subjected to Fourier-transform spectroscopy with attenuated total reflection (FTIR-ATR) in a Perkin-Elmer Spectrum 100 apparatus using the respective attachment at a resolution of $2 \mathrm{~cm}^{-1}$ accumulating up to 16 spectra for optimum signal-to-noise ratio.

${ }^{13} \mathrm{C}$ cross polarization/magic angle spinning (CP/MAS) solid state NMR spectra (ssNMR) were acquired at room temperature using a Tecmag Redstone/Bruker 300WB spectrometer operating at $75.49 \mathrm{MHz}$. Powdered samples (about $200 \mathrm{mg}$ ) were packed into $7 \mathrm{~mm}$ o. d. zirconia rotors, equipped with Kel-F caps. Spinning rate of $3.03 \mathrm{kHz}$, contact time of $2 \mathrm{msec}, 90^{\circ} \mathrm{RF}$ pulses of $4.5 \mu \mathrm{sec}$ and $10 \mathrm{~s}$ relaxation delays were selected. The number of transients was 120. ${ }^{13} \mathrm{C}$ chemical shifts were referenced with respect to external glycine whose ${ }^{13} \mathrm{C}=\mathrm{O}$ signal is observed at $176.03 \mathrm{ppm}$. Gaussian functions were chosen to iteratively deconvolute relevant signals in $\mathrm{CP} / \mathrm{MAS}$ spectra by the least-squares method using a commercial package of Microcal Software, Inc., USA.

All X-ray diffraction (XRD) patterns were collected in a Bruker D8 Discover $\theta-\theta$ diffractometer working with $C u K \alpha$ radiation $(\lambda$ $=1.541 \AA$ ). XRD patterns were collected in the $2 \theta$ range of $5-45^{\circ}$ with a step time of $1 \mathrm{~s}$ and step size of $0.2 \mathrm{deg} / \mathrm{min}$. Curve fitting of the XRD patterns was made as previously shown [18] using the package of Seasolve Software, Inc., USA. The XRD crystallinity index $X_{c}^{X R D}$ was calculated according to Eq. (2):

$X_{c}^{X R D}=\frac{\sum A_{c}}{\sum A_{c}+\sum A_{a}}$

where $\sum A_{c}$ is the integrated area underneath the respective crystalline peaks and $\sum A_{a}$ is the integrated area of the amorphous halo(s).

\subsection{Protein adsorption studies}

Bovine serum albumin (BSA) was selected as a model to study the protein adsorption on the newly synthesized PA4 MP and HMP. All experiments were conducted in batches for $1 \mathrm{~h}$, at $37^{\circ} \mathrm{C}$ at a constant shaking rate. In a typical adsorption experiment, an appropriate amount of $1 \mathrm{wt}$.\% BSA in $0.1 \mathrm{M}$ saline phosphate buffer with $\mathrm{pH} 7$ was placed into a tube and then $0.1 \mathrm{~g}$ of PA4 MP or HMP were added. After $1 \mathrm{~h}$ incubation time, the PA4 particles were removed and the supernatant was subjected to UV/VIS analysis in a Shimadzu spectrometer. The amount of BSA adsorbed onto the microparticles (i.e., the adsorption capacity, in $\mathrm{mg}$ protein per gram polyamide substrate) was determined by measuring the initial and final concentrations of BSA determined by its absorbance at $286 \mathrm{~nm}$ using a previously prepared calibration curve. The adsorption efficiency of the PA4 microparticles was calculated as a percentage of the ratio of the amounts of the adsorbed protein and that in the initial feed solution.

\section{Results and discussion}

The method to prepare PA4 microparticles for biotechnological applications is supposed to exclude any organic solvent, emulsifiers or other environmentally unfriendly components. Also, the polymerization should be carried out at mild conditions so as to preserve the structure and functional properties of the bioactive entities if the latter should be entrapped into the forming polymer substrate during the polymerization. The method suggested in this work is in good agreement with these requirements. It is based on AAROP of $2 \mathrm{PD}$ carried out at $40^{\circ} \mathrm{C}$ in the presence of the respective payload, using the proper monomer as a solvent and without the need of emulsifier.

\subsection{General observations on the 2PD anionic polymerization to MP}

The chemical structures of the 2PD, C20 activator, DL anionic initiator and the theoretical composition of the forming PA4 macromolecule are presented in Fig. 1.

As well-known from numerous previous studies mostly with $\varepsilon$-caprolactam [19], the AAROP involves a reaction of the lactam anion initiator DL with the imide links $-\mathrm{C}(\mathrm{O})-\mathrm{N}-\mathrm{C}(\mathrm{O})$ of the activator $\mathrm{C} 20$, followed by fast proton exchange of the adduct with a monomer and restauration of the initiating anion. The result of this reaction sequence is the propagation of PA4 chain. Having in mind that the C20 compound contains two imide links, chain propagation in both directions should be expected, which explains the necessity of a 2:1 mol ratio of the DL:C20. Hence, as schematically shown in Fig. 1 in red, each PA4 macromolecule would contain a moiety originating from C20. Increasing the amount of the activator C20 while keeping the $\mathrm{DL}: \mathrm{C} 20=2$ (Table 1 ), results in a slight reduction of the intrinsic viscosity $[\eta]$ measured after $6 \mathrm{~h}$ of 

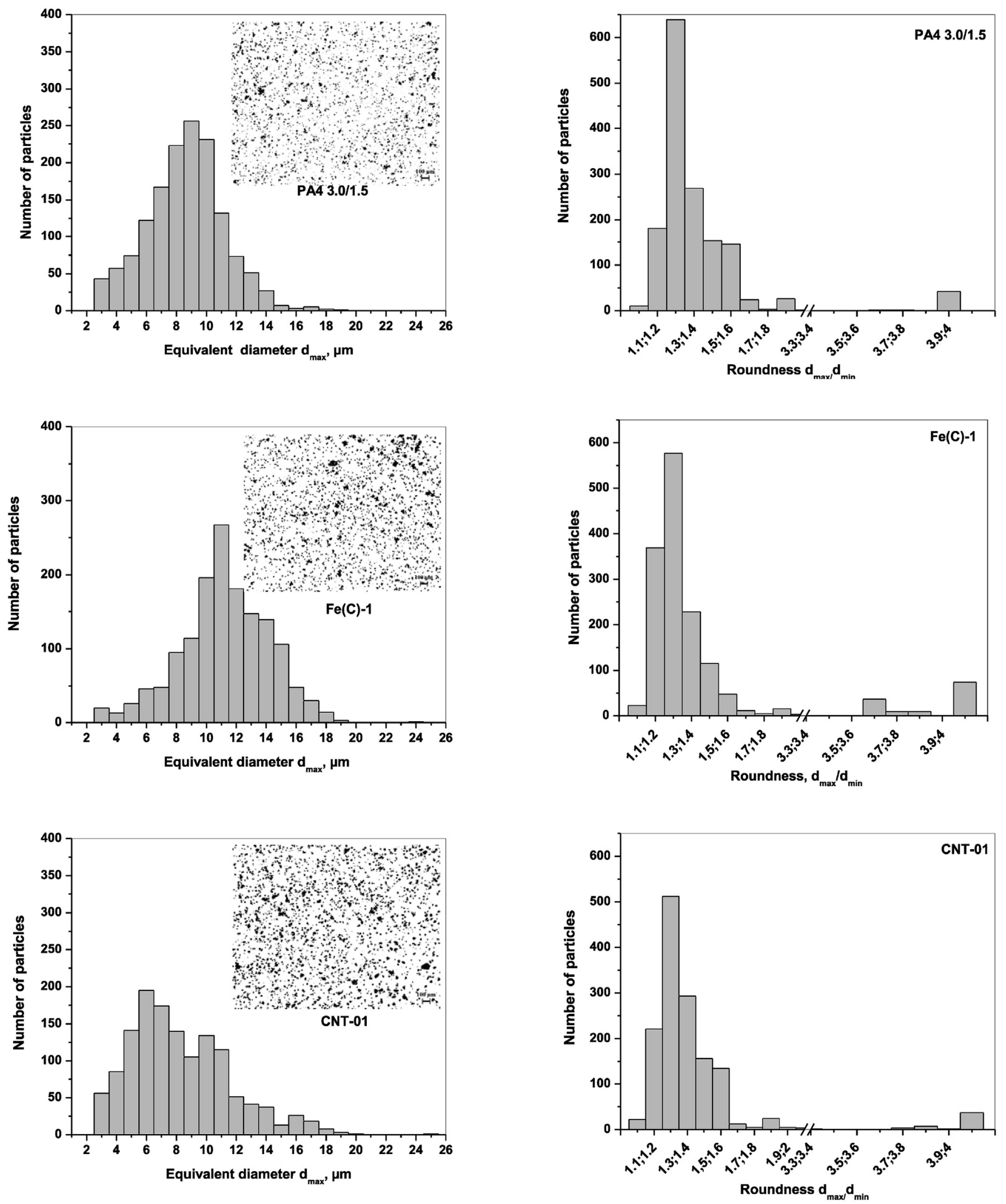

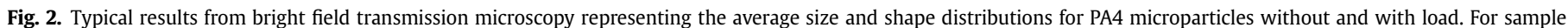
designation see Table 1. 
reaction time indicating a molecular weight decrease. Increasing the reaction time to $24 \mathrm{~h}$ levels off this trend and leads to similar viscosities for all samples.

The present study confirms the relatively low ability of 2PD to polymerize in an AAROP process. It was initially explained by Sekiguchi et al. [20] with the hydrogen-bond-based network formed by the resulting PA4 macromolecules even at a low stage of conversion. This network encages the active site of the growing chain and thus hinders the access of lactam anion. Moreover, the same authors suggest that the AAROP of 2PD will not be governed by the thermodynamic equilibrium between the cyclic monomer and the linear polymer but by the rates of the alkaline hydrolysis of the 2PD and the imide compound by the initiator [20], i.e., it will depend on the type of the activating anion. Therefore, the proper selection of the initiator for the preparation of PA4 microparticles by AAROP was the major issue to resolve in this work.

Since the $\mathrm{C} 20$ active imide compound belongs to the group of the fast activators, to obtain microparticles and not fused agglomerates or chunks of bulk polymer, a relatively slow initiator was selected, as suggested in earlier works on anionic PA6 powders [21]. Due to the coordination of the lactamate anion with the aluminum ligand (Fig. 1), a decreased nucleophilicity is achieved in DL combined with effective delocalization of the negative charge. The bulky anion of DL was expected to have two advantages in the AAROP of 2PD: (i) to be more difficult to get inactivated by acidic contaminations of the reaction mixture so typical for the simple alkali caprolactamate salts, and (ii) to decrease the supposed effect of encaging the active growing chain end. In fact, the present study proves that using the DL/C20 catalytic system allows the successful solventless synthesis of PA4 MP or HMP at temperatures as low as $40^{\circ} \mathrm{C}$. The presence of various inorganic payloads does not inactivate the catalytic system.

\subsection{Microparticles formation and morphology}

The formation of PA6 microparticles in the process of AAROP in a hydrocarbon solvent was explained in an earlier study [22]. According to it, initially the growing polyamide chains fold and form viscous droplets representing coiled oligomer molecules. These droplets, upon additional chain propagation, coalescence and crystallization, produce the final semicrystalline microparticles. It can be hypothesized that the formation of PA4 neat MP will follow a similar pathway. Any metal, metal oxide or carbon load particle will be entrapped into the viscous PA4 coiled structures and will
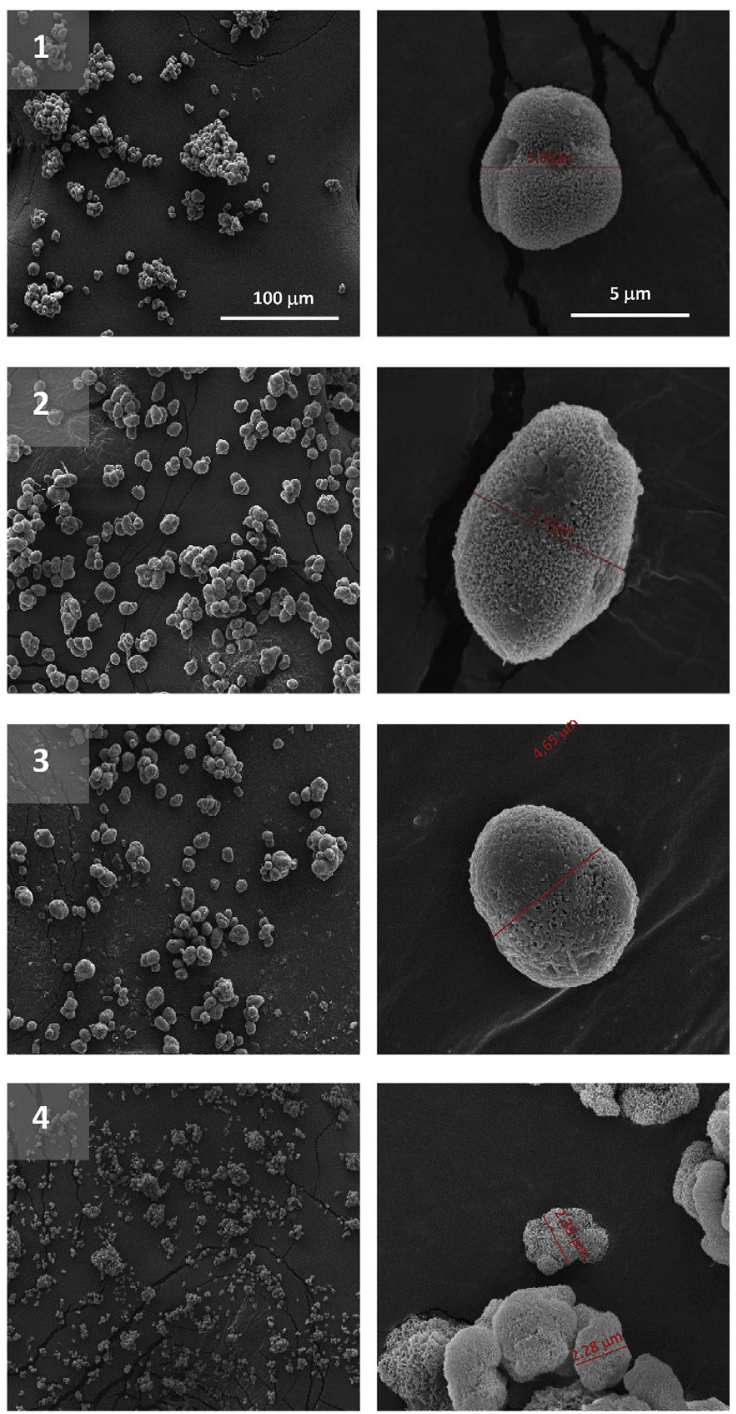
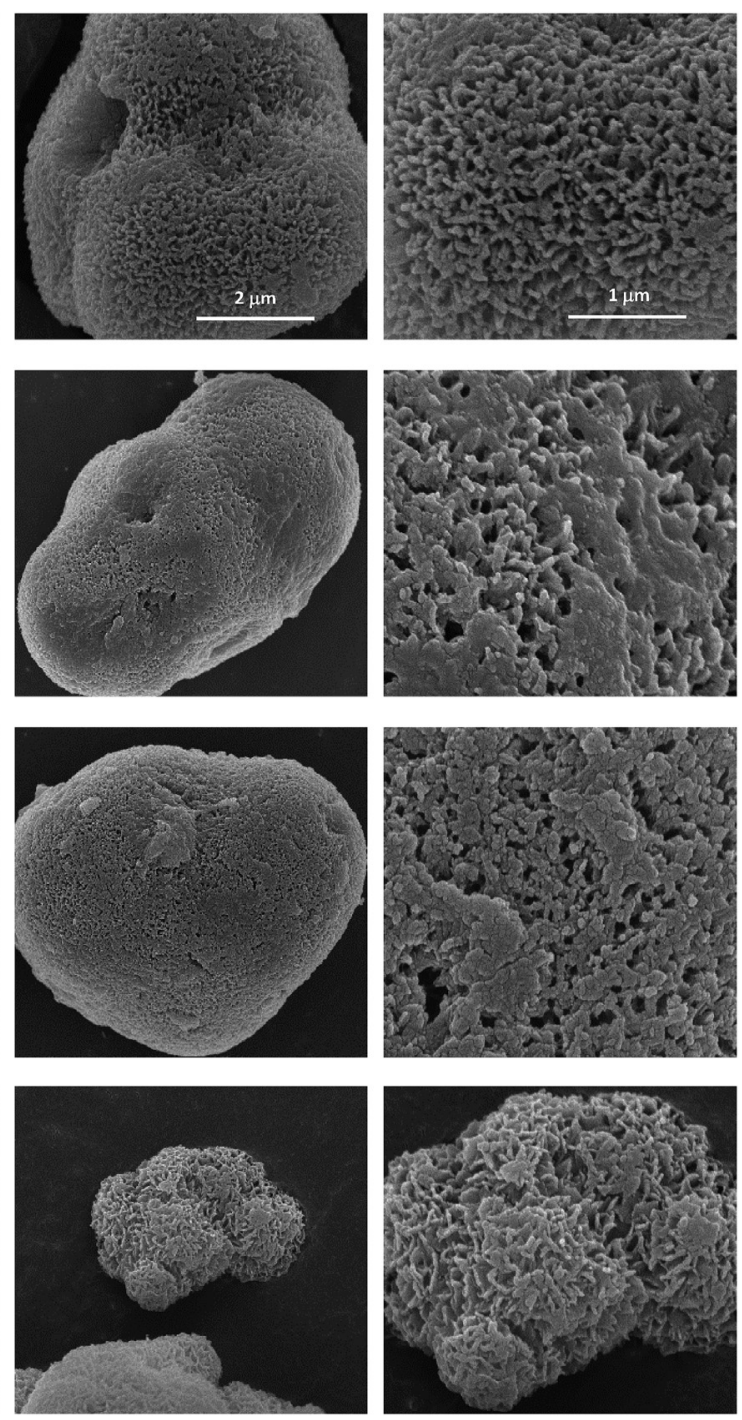

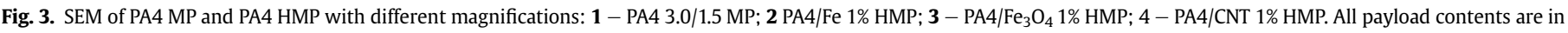
wt.\% in respect to 2-PD. The real contents of payloads $R L$ are presented in Table 1. 
possibly nucleate their crystallization thus forming shell-core hybrid PA4 particles. PA4 yields (in respect to the monomer 2PD) in the range of $44-58 \%$ for neat MP and $55-64 \%$ for PA4 hybrid MP were obtained (Table 1). Provided that the whole amount of the solid loads ( $1 \mathrm{wt}$. \% in respect to 2PD for all samples except for CNT with $0.1 \mathrm{wt} \%$ ) is included into the microcapsules, such PA4 yields increase the real loads (RL) by $60-100 \%$. Factors such as loss of magnetic particles before their being covered by PA4 or increased char formation at $600{ }^{\circ} \mathrm{C}$ in the presence of $\mathrm{Cu}$ or $\mathrm{CNT}$ loads during the TGA experiment should also be considered in explaining the RL
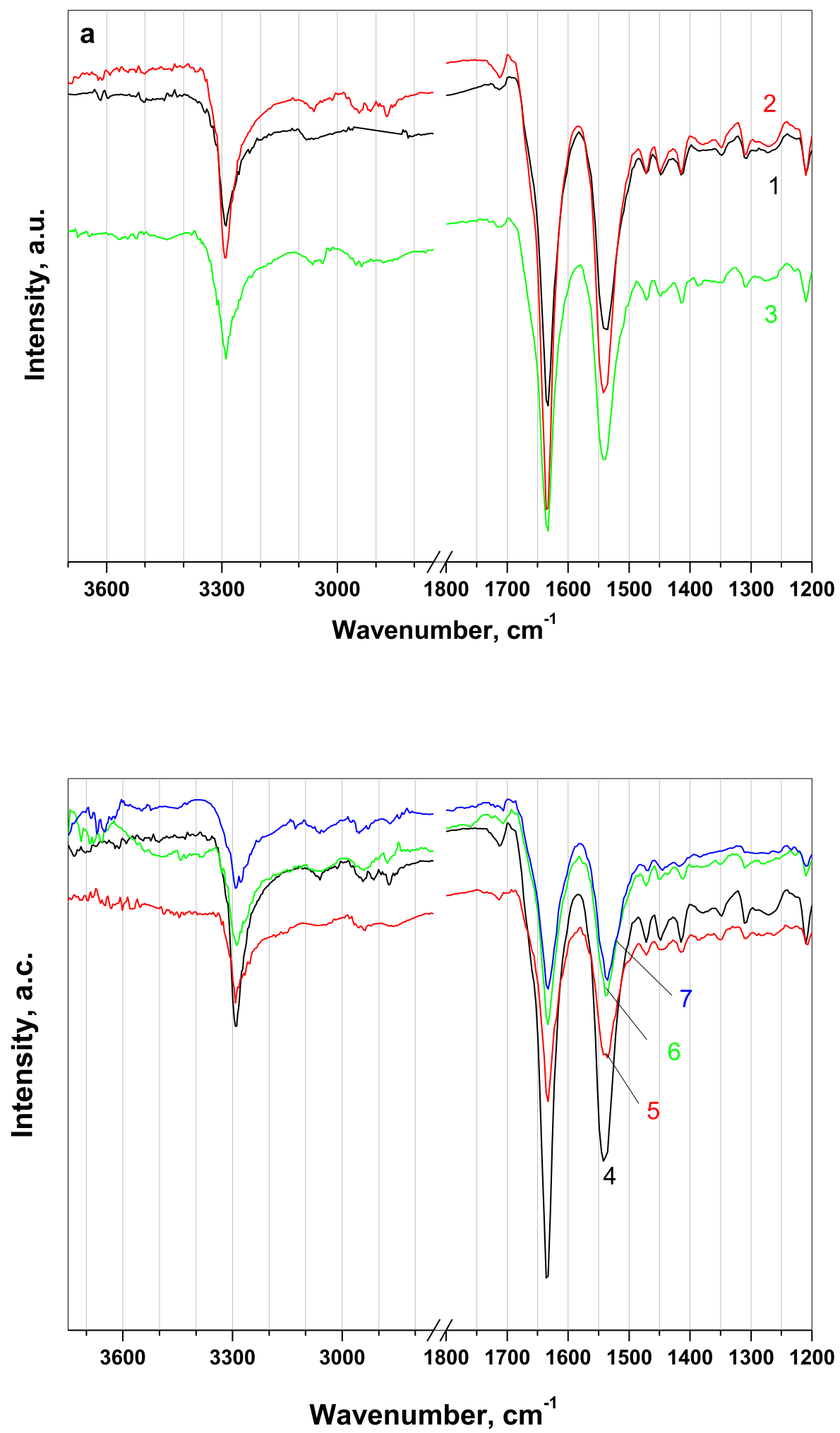

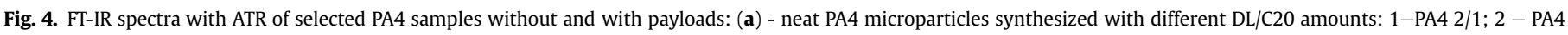
3.0/1.5; 3 - PA4 4/2; (b) - PA4 microparticles loaded with: 5 - uncoated Fe; 6 - phosphate coated Fe; 7 - Cu. Sample 4 is the neat PA4 with DL7C20 = 3.0/1.5. 
values in Table 1.

The histograms related to the size distribution of equivalent diameters and roundness obtained by bright field optical microscopy are presented in Fig. 2. The insets in the graphs of the lefthand side demonstrate the stereoscopic micrograph of MC based on which the size distribution was computed. Table 1 shows data about the distribution of particles size (maximum diameter) and shape (roundness) for all PA4 microparticles.

Analyzing the data in Fig. 2 and Table 1 allows the conclusion that the $d_{\max }$ values of the neat PA4 microparticles range between 6 and $12 \mu \mathrm{m}$. The sample PA4 2/1 with the lowest amount of catalytic system displays a bimodal size distribution with peaks at 4-6 and 10-12 $\mu \mathrm{m}$, whereas the other two neat PA4 samples the distribution is normal with $d_{\max }$ values of $6-10 \mu \mathrm{m}$. The reason might be the difference in the molecular weight of the PA4 molecules in the moment of MC crystallization. The average shape of the neat PA4 particles is elliptical their roundness varying in the 1.1-1.3 range.

In the hybrid MPs systems, the finest particle sizes of 5-9 $\mu \mathrm{m}$ are registered with the nanosized $\mathrm{CNT}$ and $\mathrm{Fe}_{3} \mathrm{O}_{4}$ loads. The $\mathrm{Cu}$ and $\mathrm{Fe}$ and $\mathrm{Fe}(\mathrm{C}) \mathrm{HMP}$ display broader size distributions reaching $12 \mu \mathrm{m}$. This should be related with the proper sizes of the $\mathrm{Cu}$ and Fe particles being $>10 \mu \mathrm{m}$ and $3-4 \mu \mathrm{m}$, respectively, meaning that the $\mathrm{Cu}-1 \mathrm{MP}$ would contain one metal particle in the core and the Fe-1 and $\mathrm{Fe}(\mathrm{C})-1$ - up to 3 core particles. Interestingly, the roundness distribution histograms of all magnetic HMP contain small amounts of structures with aspect ratios of 3.2-4.1. Most probably, the magnetic load particles stick to one another in the magnetically stirred reaction media of the AAROP and then get covered by PA4 as the polymerization advances.

More details on the MP morphology could be obtained by SEM. Fig. 3 shows the SEM micrographs at various magnifications of neat PA4 MP and of HMP based on PA4 carrying different fillers. The SEM micrographs in the first row display the PA4-3.0/1.5 sample with single microparticles of $5-10 \mu \mathrm{m}$ and almost spherical shapes. Higher magnification images visualize the porous morphology of the neat MP, the visible diameters of the pores being in the 50-90 nm range and a specific "hairy" surface.

When a payload of Fe is introduced (row 2), the average particles size grows above $10 \mu \mathrm{m}$, the shape of the HMP becoming less spherical. Such structures cannot be fragmented by smashing and confirm the self-assembly of magnetized load particles with their subsequent coating with PA4. The average visible diameters of the pores of the Fe-containing HMP is larger than those of the neat MP, clearly above $120-150 \mathrm{~nm}$. Very similar are the HMP with $\mathrm{Fe}_{3} \mathrm{O}_{4}$ load shown in row 3 and with $\mathrm{Cu}$ (not shown in Fig. 3). Since according to the data from EDX the load particles are not found on the surface, they should have been entrapped in the core of the MP thus confirming the supposed mechanism of the HMP formation.

The introduction of the nanosized CNT filler into the PA4 microparticles (row 4) results in very small HMP with sizes around 3-4 $\mu \mathrm{m}$. In this particles the porous structure cannot be observed due to the formation of a specific labyrinth-like morphology on their surface. It should be noted that this is the only non-metal load used in this work. The morphology of the PA4/CNT microparticles is very similar to that of PA6/CNT HMP synthesized in our previous works [23].

\subsection{Chemical structure studies}

The chemical structure of the newly synthesized MP and HMP was confirmed by FT-IR and solid state NMR analyses.

All FT-IR spectra of PA4 microparticles without (Fig. 4a) or with payloads (Fig. 4b) display the general characteristic peaks of a polyamide: at ca. $3289 \mathrm{~cm}^{-1}$ for associated $\mathrm{N}-\mathrm{H}$ groups, and the Amide I and Amide II groups at $1635 \mathrm{~cm}^{-1}$ and $1535 \mathrm{~cm}^{-1}$, respectively.



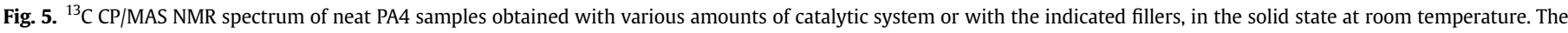
asterisks denote spinning sidebands. 
Table 2

${ }^{13} \mathrm{C}$ chemical shifts (ppm) of the PA4 microparticles without and with payloads.

\begin{tabular}{llllll}
\hline \multirow{2}{*}{ No } & Sample & \multicolumn{4}{l}{ Chemical shift $\delta$, ppm } \\
\cline { 3 - 6 } & & C1 & C2 & C3 & C4 \\
\hline 1 & PA4 3.0/1.5 & 41.85 & 22.68 & 33.13 & 172.54 \\
2 & PA4 2/1 & 41.85 & 22.68 & 33.13 & 172.54 \\
3 & PA4 4/2 & 41.85 & 22.90 & 33.53 & 172.76 \\
& & $39.5^{\mathrm{a}}$ & $25.9^{\mathrm{a}}$ & & $174.7^{\mathrm{a}}$ \\
4 & PA4 CNT 0.1 & 41.85 & 22.68 & 33.13 & 172.54 \\
& & $39.1^{\mathrm{a}}$ & $27.3^{\mathrm{a}}$ & & $161.9^{\mathrm{b}}$ \\
5 & PA4 Cu1 & 41.41 & 22.24 & 32.92 & 172.11 \\
& & & $25.9^{\mathrm{a}}$ & & \\
6 & PA4, ref. [22] & 42.4 & 23.4 & 34.0 & 173.3 \\
& & $39.7^{\mathrm{a}}$ & $26.4^{\mathrm{a}}$ & $34.0^{\mathrm{a}}$ & \\
\hline
\end{tabular}

a Broad signal, non-crystalline contribution.

b Not assigned.

The inclusion of a payload does not change the position or the relative intensities of these absorption bands. It seems, however, that the Amide I and Amide II bands of the hybrid PA4 particles (Fig. 4b) are slightly wider than in the neat PA4 samples which can be explained with the sample inhomogeneity in the former case.

A common feature of all samples in Fig. 4 is the presence of small but detectable bands in the $1710-1713 \mathrm{~cm}^{-1}$ range characteristic for the $\mathrm{C}=\mathrm{O}$ stretching vibrations of terminal carboxylic groups. In theory, if no side reactions take place, the propagation of the PA4 chain would repeat until the exhaustion of the lactam monomer. The final PA4 macromolecule would terminate as depicted in Fig. 1, i.e., by two $2 \mathrm{PD}$ rings, with regeneration of both active species - the imide links at the terminuses and the initiating anion. The observed appearance of terminal $\mathrm{COOH}$ groups can be a result of the opening of the $\mathrm{C}-\mathrm{N}$ bond in the terminal imide links. This can happen during the polymerization or the isolation of the PA4 due to hydrolysis.

Another technique that proved the chemical structure of the PA4 microparticles of this study was the solid state NMR. The ${ }^{13} \mathrm{C}$ $\mathrm{CP} / \mathrm{MAS}$ spectra of the neat PA4 samples with variation of the amount of the catalytic system or the filler type are depicted in Fig. 5.

Asymmetric signals are observed for carbons C1-C4 that reflect the presence of superimposed resonances of crystalline and noncrystalline components producing narrow and broad resonance lines, respectively. Table 2 presents the chemical shifts obtained from the spectra in Fig. 5. For all neat PA4 samples, the ${ }^{13} \mathrm{C}$ chemical shift assignments of the narrow lines follow a previously reported detailed NMR study on PA4 [24]. In the PA4 4/2 sample prepared with maximum amount of catalytic system, broad non-crystalline signals are observed at about $39 \mathrm{ppm}$ and $26 \mathrm{ppm}$ being assigned to the $\mathrm{C} 1$ and $\mathrm{C} 2$ carbons, respectively.

As demonstrated in Ref. [24], the appearance of these signals shifted to lower field by about $3 \mathrm{ppm}$ and to higher field by about $2 \mathrm{ppm}$ as compared to the crystalline counterparts should be correlated with conformational changes between crystalline and non-crystalline states. The crystalline PA4 material presents narrow resonance with all-trans conformation of the macromolecules while in the amorphous PA4 phase a fast transition from trans to gauche conformation occurs resulting in broader resonances [24]. The PA4 samples of this study containing CNT and Cu loads also display non-crystalline peaks for $\mathrm{C} 1$ and/or C2.

Table 2 shows that from the neat PA4 samples only PA4 4/2 displays a broad signal for the carbonyl C-atoms originating from non-crystalline PA4 material. In the other two neat PA4 samples, as

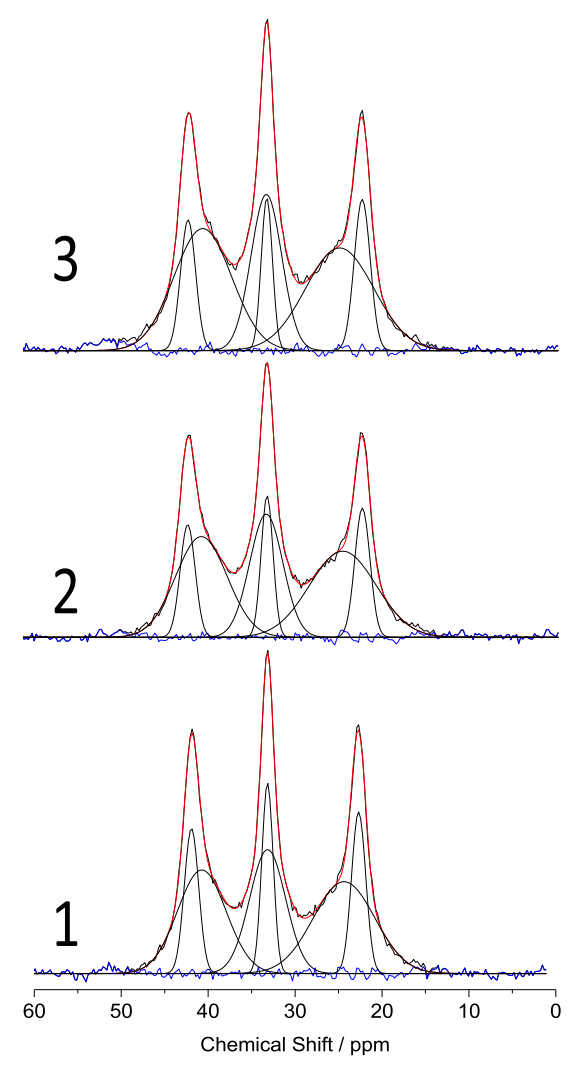

$$
\begin{aligned}
& \text { 1-PA4 3.0/1.5 } \\
& \text { 2-PA4 2/0 } \\
& \text { 3-PA4 4/2 } \\
& 4 \text { - PA4 CNT } 0.1 \\
& \text { 5-PA4 CU } 1
\end{aligned}
$$

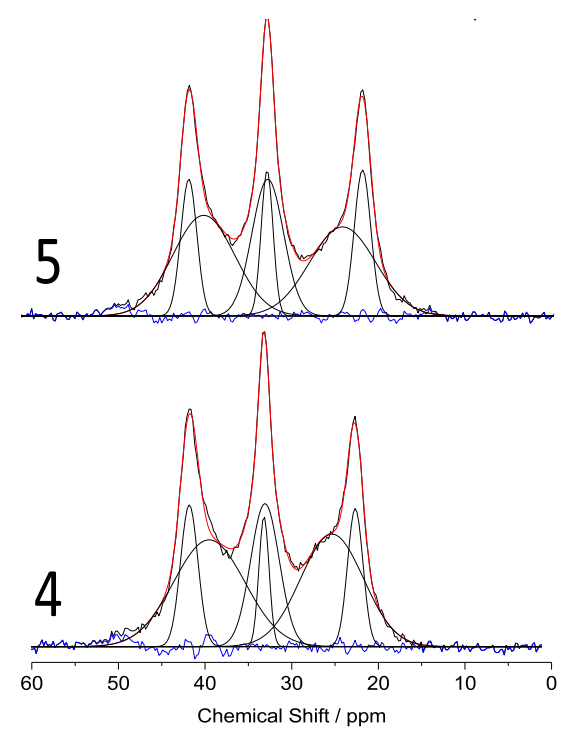

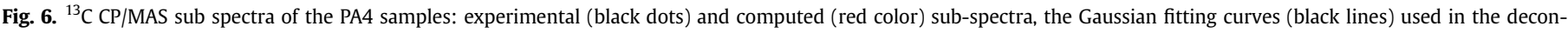

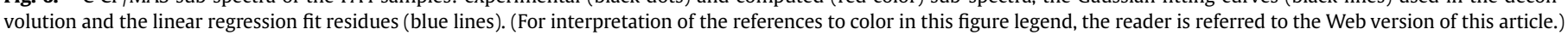


Table 3

Degree of crystallinity in \% of PA4 samples obtained by peak fitting of solid state NMR data.

\begin{tabular}{lllll}
\hline No & Sample & C1 & C2 & C3 \\
\hline 1 & PA4 3.0/1.5 & $29.12 \pm 2.20$ & $28.55 \pm 0.89$ & $32.58 \pm 1.45$ \\
2 & PA4 2/1 & $24.40 \pm 2.07$ & $25.51 \pm 0.72$ & $28.51 \pm 3.21$ \\
3 & PA4 4/2 & $21.65 \pm 2.00$ & $25.45 \pm 0.93$ & $25.62 \pm 3.69$ \\
4 & PA4 CNT 0.1 & $24.33 \pm 1.16$ & $22.97 \pm 1.09$ & $23.84 \pm 2.79$ \\
5 & PA4 Cu 1 & $25.96 \pm 1.67$ & $28.97 \pm 0.92$ & $27.82 \pm 3.37$ \\
\hline
\end{tabular}

well as in the Cu-loaded HMP a single crystalline peak was only observed. The weak resonance line at ca. $162 \mathrm{ppm}$ in the CNTloaded HMP remained unassigned.

The non-quantitative nature of $\mathrm{CP} / \mathrm{MAS}$ experiments is generally accepted. Carbon magnetization is enhanced by the strongly polarized hydrogen nuclei and consequently signal intensity depends on the multiplicity of carbon atoms. Direct observation of carbon resonances (Bloch decay, without $\mathrm{CP}$ ) is preferred to obtain quantitative data [25]. Because magnetization recovery is controlled by the ${ }^{13} \mathrm{C}$ spin-lattice relaxation, these experiments demand very long acquisition times. Semi-quantitative data, however, may be extracted from $\mathrm{CP}$ spectra when comparing the intensities of carbons with the same multiplicity.

Thus, the degree of crystallinity of five selected PA4 MP and HMP samples was obtained on the basis of the methylene carbon signals in the following way. First, these three signals were deconvoluted using Gaussian functions. The experimental chemical shifts shown in Table 2 were used as initial values and the same full width at half maximum (FWHM) was assigned to the C1 and C2 broad components. Fig. 6 shows the experimental and the computed sub-spectra, the convoluted Gaussian curves, and the linear regression fit residues. Table $1 \mathrm{~S}$ (submitted as supplementary material) presents the parameters of the Gaussian curves. Second, the percentage of the degree of NMR crystallinity was determined using the integrals of the crystalline and amorphous PA4 phases obtained from each carbon. The results are shown in Table 3.

The solid state NMR data allow the conclusion that from the neat PA4 samples the one with the DL/C20 $=3.0 / 1.5$ is with the highest crystallinity, close to $30 \%$. The NMR crystallinity of the $\mathrm{Cu}-$ containing HMP is only slightly lower, whereas that with the CNT payload seems to be the less crystalline.

This finding allows to hypothesize that the crystallizability of the PA4 will depend on the molecular weight in the case of homogeneous nucleation, while in the case of heterogeneous nucleation - on the nature of the filler as well.

\subsection{Crystalline structure and thermal properties}

The high melting temperature of PA4 obtained by a bulk AAROP process has been reported by many authors indicating $T_{m}$ values in the $257-268^{\circ} \mathrm{C}$ range, always preceded or accompanied by thermal degradation $[5,7,26]$.

Notably, all samples of the present study on PA4 microparticles displayed dual melting behavior, i.e., a lower and a higher melting peak, whose position and shape depended on the AAROP temperature. Fig. 7 shows the first DSC scan of two neat MP samples synthesized by the solventless method at a lower polymerization temperature of $40^{\circ} \mathrm{C}$ designated as LTP and such prepared at $60^{\circ} \mathrm{C}$ and designated as HTP.

Both samples displayed very clear dual melting behavior. In the HTP sample, quite narrow melting endotherms at $206^{\circ} \mathrm{C}$ and $243^{\circ} \mathrm{C}$ were observed followed by a broader endotherm of degradation with onset at $250^{\circ} \mathrm{C}$. In the LTP sample the lower melting peak is much broader and appears in the range of $193-203^{\circ} \mathrm{C}$. Judging from the shape of the second endotherm at $262^{\circ} \mathrm{C}$, it is superimposed with that of massive degradation event. This dual melting behavior of the HTP and LTP microparticles indicates the presence of two populations of PA4 crystallites. In the AAROP at $60^{\circ} \mathrm{C}$ performed for $6 \mathrm{~h}$ both populations are quite perfect while the LTP process performed for $6 \mathrm{~h}$ at $40^{\circ} \mathrm{C}$ produces apparently less perfect or smaller crystallites. The reasons of the double melting behavior could be related to the formation of crystalline lamellae with different thickness and degree of ordering containing PA4 macromolecules of different molecular weights, as well as to polymorphism. It should be noted that both samples in Fig. 7 do not show any melting during a second DSC scan which is a proof of intense degradation during the first one.

To get more information about the crystallizability of the neat and hybrid PA4 microparticles, the region of the first melting endotherm for all samples was studied applying a DSC heating scan

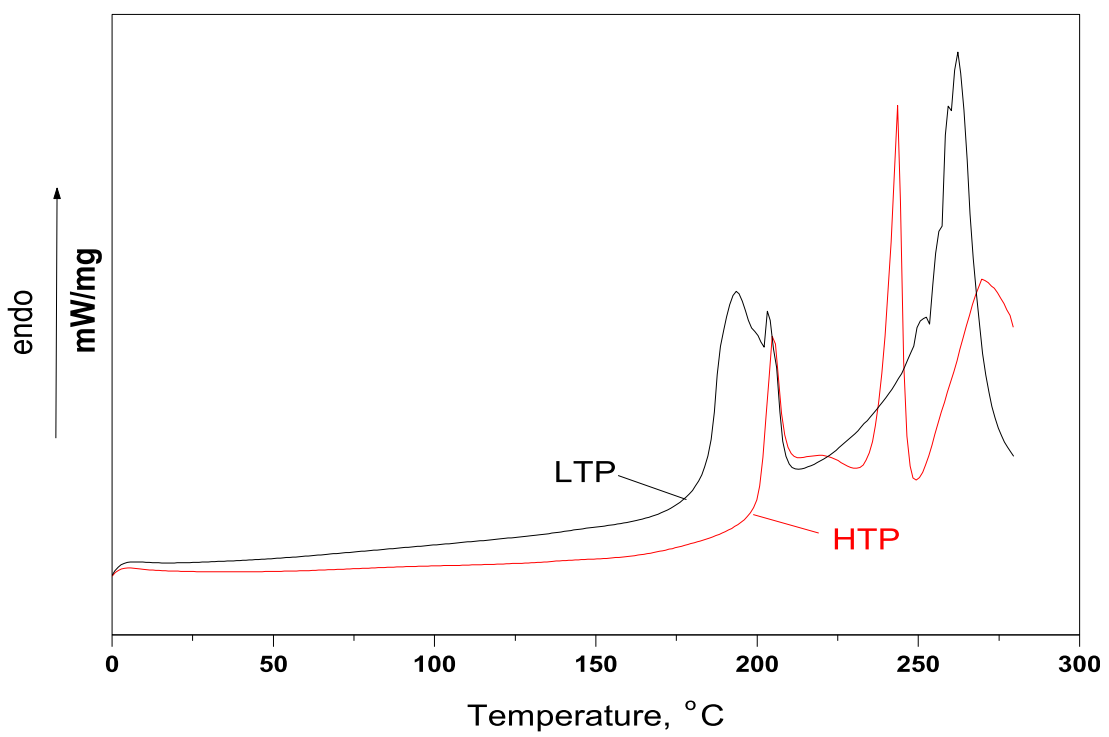

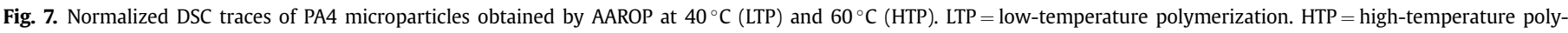
merization. $\mathrm{DL} / \mathrm{C} 20=3.0 / 1.5$, AAROP time duration $-6 \mathrm{~h}$ for HTP and $24 \mathrm{~h}$ for LTP. 
to $225^{\circ} \mathrm{C}$ (for the neat PA4 up to $205^{\circ} \mathrm{C}$ ) (Fig. 8a) thus minimizing the onset of degradation, then cooling down to $0^{\circ} \mathrm{C}$ (Fig. 8b) followed by a 2 nd heating this time to $250^{\circ} \mathrm{C}$ (Fig. 8c). All information extracted from the DSC curves was presented in Table 4.

As seen from the first heating scan, the position and especially the shape of the lower melting endotherm depend significantly on the presence of specific payloads in the PA4 HMP. Glass-transition temperatures in the range of $60-65^{\circ} \mathrm{C}$ were obtained (Table 4 ), which are higher than PA6 $\left(45-47^{\circ} \mathrm{C}\right)$ and closing to that of PA66 $\left(68-70^{\circ} \mathrm{C}\right)$. This should be related to the dense $\mathrm{H}$-bond network in the amorphous PA4 that decreases the chain mobility. Interestingly, even $0.1 \mathrm{wt} \%$ of CNT could cause a $4{ }^{\circ} \mathrm{C}$ increase of the $T_{g}$ in respect to the neat PA4, which is an indirect proof of good dispersion within the amorphous phase. Similar effect is observed with the Fe and $\mathrm{Fe}(\mathrm{C})$ particles.

According to the results of the recrystallization experiment in
Fig. $8 \mathrm{~b}$ and Table 4 , all payloads promote intense heteronucleation increasing the $T_{c r}$ from $139{ }^{\circ} \mathrm{C}$ for the neat PA4 to $165-188^{\circ} \mathrm{C}$, the effect being the strongest with the two Fe loads.

During the subsequent 2nd DSC heating (Fig. 8c) all the samples display melting peaks at $T_{m}$ with ca. $30^{\circ} \mathrm{C}$ higher than during the 1st scan. It can be therefore concluded that the crystallization/ recrystallization behavior of PA4 MP and HMP can be controlled both by the AAROP temperature and by the nature and amount of the payload particles. Unfortunately, calculation of reliable crystallinity indices of the samples in Table 4 based on DSC traces is impossible, since the melting endotherms are superimposed with massive degradation peaks.

The TGA curves of the samples are presented in Fig. 9 and the numerical data extracted from them - in Table 5. Three main degradation events take place in all MP and HMP samples: (i) at $220-236^{\circ} \mathrm{C}$; (ii) between 240 and $259^{\circ} \mathrm{C}$ and (iii) $300-327^{\circ} \mathrm{C}$.
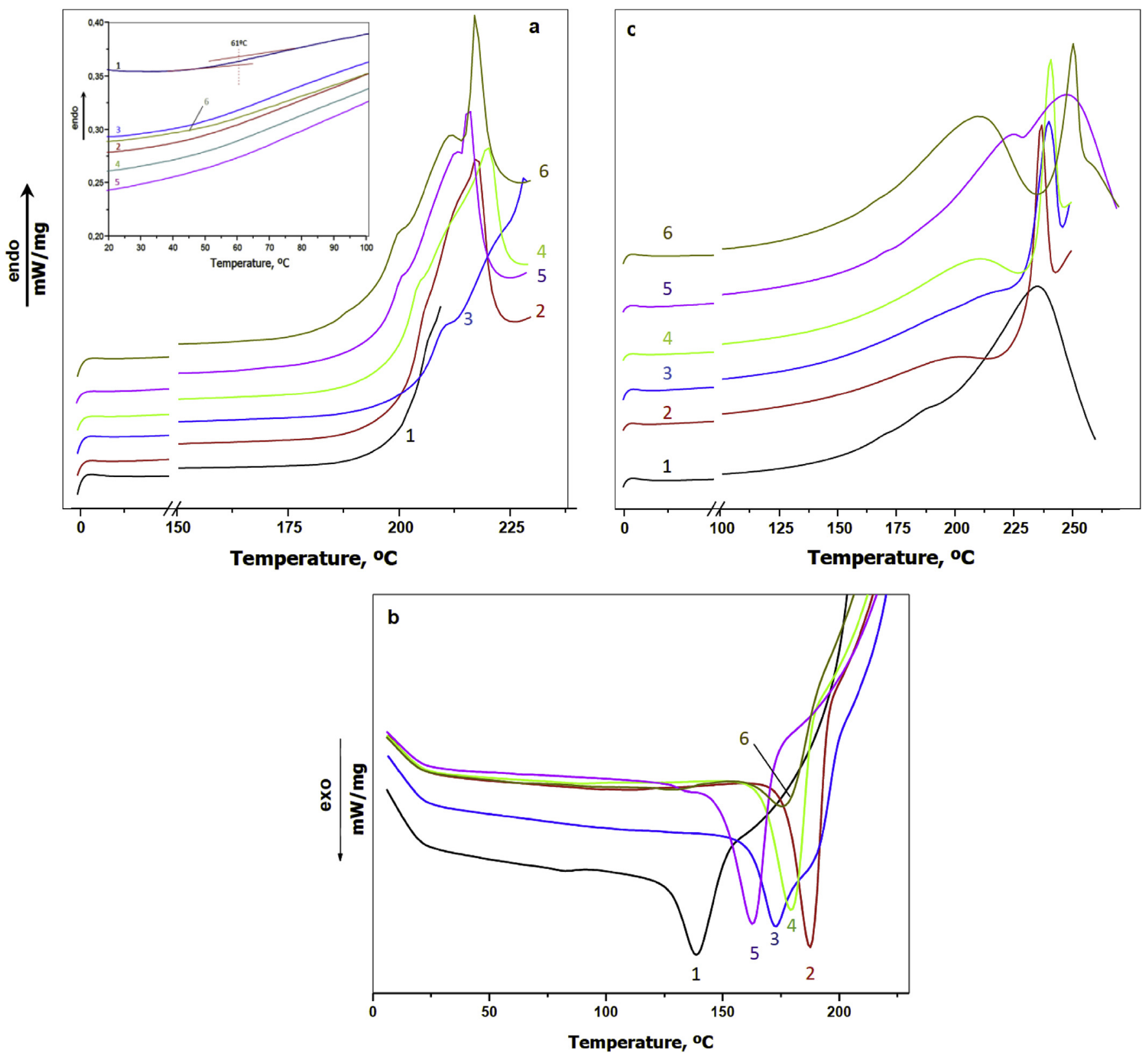

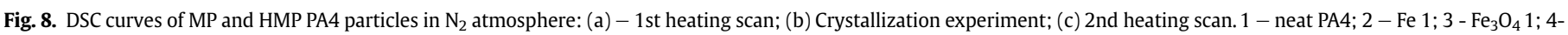
$\mathrm{Fe}(\mathrm{C})-1 ; 5-\mathrm{Cu}-1$; CNT-01. The inset in Fig. 7a shows the enlarged region of glass transition and the way $T_{g}$ was determined. For sample designation see Table 1. 
Table 4

Data from DSC about the meting temperatures $T_{m}$, glass-transition $T_{g}$ and crystallization temperatures $T_{c r}$.

\begin{tabular}{|c|c|c|c|c|c|c|}
\hline \multirow[t]{2}{*}{ Sample } & \multicolumn{2}{|c|}{ 1st heating scan } & \multicolumn{2}{|c|}{ Cooling scan } & \multicolumn{2}{|c|}{ 2nd heating scan } \\
\hline & $\mathrm{T}_{\mathrm{m}},{ }^{\circ} \mathrm{C}$ & $\mathrm{T}_{\mathrm{g}},{ }^{\circ} \mathrm{C}$ & $\mathrm{T}_{\mathrm{cr}},{ }^{\circ} \mathrm{C}$ & $-\Delta \mathrm{H}, \mathrm{J} / \mathrm{g}$ & $\mathrm{T}_{\mathrm{m}},{ }^{\circ} \mathrm{C}$ & $\Delta \mathrm{H}, \mathrm{J} / \mathrm{g}$ \\
\hline PA4 3.0/1.5 & 202.7 & 60.7 & 138.6 & 20.7 & 234.8 & 37.74 \\
\hline Fe 1 & 203.1 & 65.6 & 187.5 & 34.0 & 236.7 & 23.4 \\
\hline $\mathrm{Fe}_{3} \mathrm{O}_{4} 1$ & 216.3 & 60.2 & 169,1 & 23.7 & 245.8 & 21.7 \\
\hline $\mathrm{Fe}(\mathrm{C}) 1$ & 210.6 & 66.2 & 179.3 & 27.8 & 240.7 & 23.2 \\
\hline $\mathrm{Cu} 1$ & 221.5 & 59.6 & 165.1 & 28.6 & 248.3 & 15.6 \\
\hline CNT 0.1 & 217.0 & 64.6 & 175.4 & 34.3 & 250.1 & 15.2 \\
\hline
\end{tabular}

It can be seen that the presence of payloads does stabilize the PA4 matrix. All initial degradation temperatures $T_{d e g}^{\text {in }}$ of HMP are higher than that of the neat MP (Table 5), whereby the CNT01 and Cu1 samples showed the larger enhancement with $\Delta T_{\text {deg }}^{\text {in }}=11$ $12^{\circ} \mathrm{C}$. With the temperature of maximum degradation $T_{d e g}^{\max }$, the enhancement $\Delta T_{d e g}^{\max }=18-25^{\circ} \mathrm{C}$, depending on the degradation event considered. As mentioned above in Table 1, the real payload content RL calculated according to Eq. (1) in all hybrid microparticles is higher than the theoretical $-0.1 \mathrm{wt} . \%$ for CNT and $1 \mathrm{wt} . \%$ for all other HMP. This can be explained with the fact that all of the payload amount is entrapped into the forming polymer and the degree of conversion of 2PD to PA4 is lower than $100 \%$.

\subsection{Crystalline structure by X-ray scattering}

There exist very few and already dated XRD studies on the crystalline structure of PA4. As early as 1966 Fredericks et al. suggested the existence of three polymorphs. The $\alpha$-PA4 with extended planar zig-zag conformation of chains and monoclinic unit cell similar to the $\alpha$-PA6 was found to predominate in highly crystalline and oriented filaments [27]. Two less perfect crystalline forms designated as $\beta$ - and $\delta$-polymorphs with hexagonal packing of chains were detected at temperatures close to the melting point or after quenching [28], but no unit cell parameters or d-spacing values were reported. It is important to note, that according to refs. $[27,28]$ the said $\beta$ - and $\delta$-polymorphs do not co-exist with the more thermodynamically stable and perfect $\alpha$-PA4. Three decades later, Bellinger et al. [29] have revisited the PA4 crystalline structure in single crystals confirming the monoclinic crystalline cell of the $\alpha$ PA4 with $d_{\alpha[200]}=0.44 \mathrm{~nm}$ and $d_{\alpha[020]}=0.37 \mathrm{~nm}$. The authors concluded that the PA4 chains are parallel to the lamellar normal and that the amide group is incorporated in the fold. Such incorporation does not take place in other polyamides such as PA6 or PA66, however it is very typical for the $\beta$-bends in proteins [29]. No newer XRD studies on PA4 assessing the polymorph content by pattern deconvolution were found.

In our XRD studies such a deconvolution by peak fitting was performed in all PA4 MP and HMP patterns. Fig. 10 displays the fits in three selected samples. All crystallographic data extracted from

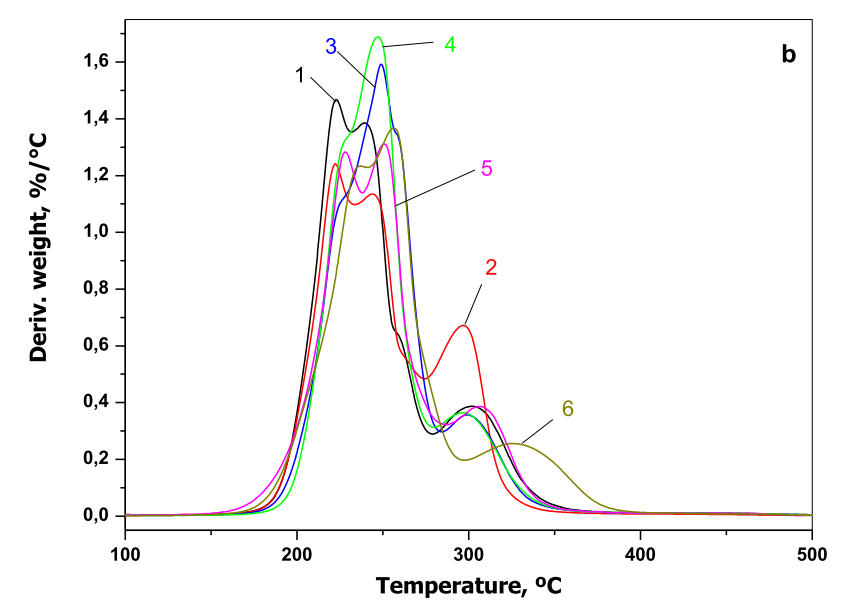

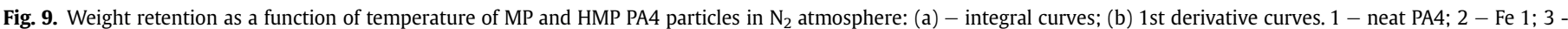
$\mathrm{Fe}_{3} \mathrm{O}_{4} 1 ; 4-\mathrm{Fe}(\mathrm{C})-1 ; 5-\mathrm{Cu}-1$; CNT-01. For sample designation see Table 1.

Table 5

TGA analysis of PA4 MP and PA4 HMP.

\begin{tabular}{|c|c|c|c|c|c|c|}
\hline \multirow[t]{2}{*}{ Sample designation } & \multirow[t]{2}{*}{ Temp. of $5 \%$ loss, $\mathrm{T}_{5 \%},{ }^{\circ} \mathrm{C}$} & \multirow[t]{2}{*}{ Temp. of Initial degradation $\mathrm{T}^{i n}{ }_{\mathrm{deg}},{ }^{\circ} \mathrm{C}$} & \multicolumn{3}{|c|}{$\begin{array}{l}\text { Temp. of max. degradation } \mathrm{T}^{\max } \text { deg, } \\
{ }^{\circ} \mathrm{C} \text { Deriv. weight change, } \% /{ }^{\circ} \mathrm{C}\end{array}$} & \multirow[t]{2}{*}{ Residue at $600^{\circ} \mathrm{C}, \%$} \\
\hline & & & $\mathrm{I}$ & II & III & \\
\hline PA4 & 196.52 & 205.35 & $\begin{array}{l}223.19 \\
1.467\end{array}$ & $\begin{array}{l}240.59 \\
1.383\end{array}$ & $\begin{array}{l}301.14 \\
0.387\end{array}$ & 1.116 \\
\hline $\mathrm{Fe}-1$ & 193.27 & 206.71 & $\begin{array}{l}222.43 \\
1.241\end{array}$ & $\begin{array}{l}243.62 \\
1.135\end{array}$ & $\begin{array}{l}296.59 \\
0.672\end{array}$ & 3.165 \\
\hline $\mathrm{Fe}_{3} \mathrm{O}_{4}-1$ & 206.23 & 210.9 & $\begin{array}{l}226.21 \\
1.114\end{array}$ & $\begin{array}{l}248.92 \\
1.597\end{array}$ & $\begin{array}{l}298.86 \\
1.592\end{array}$ & 2.716 \\
\hline $\mathrm{Fe}(\mathrm{C})-1$ & 204.23 & 212.03 & $\begin{array}{l}229.24 \\
1.333\end{array}$ & $\begin{array}{l}247.40 \\
1.688\end{array}$ & $\begin{array}{l}297.35 \\
0.384\end{array}$ & 2.316 \\
\hline $\mathrm{Cu}-1$ & 192.53 & 216.09 & $\begin{array}{l}233.75 \\
1.411\end{array}$ & $\begin{array}{l}253.25 \\
1.399\end{array}$ & $\begin{array}{l}318.50 \\
0.334\end{array}$ & 3.616 \\
\hline CNT - 01 & 199.91 & 217.21 & $\begin{array}{l}236.44 \\
1.233\end{array}$ & $\begin{array}{l}258.82 \\
1.367\end{array}$ & $\begin{array}{l}326.57 \\
0.256\end{array}$ & 1.416 \\
\hline
\end{tabular}



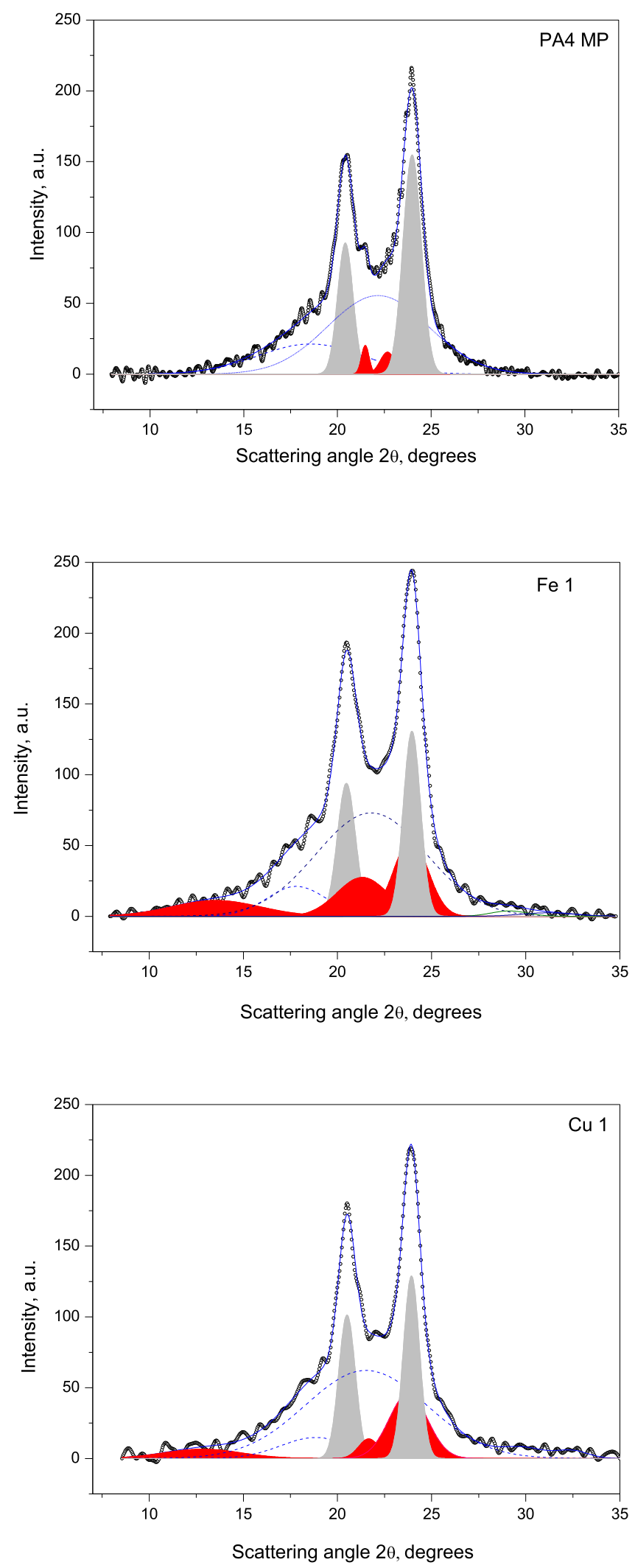

Fig. 10. Deconvolution by peak fitting of three selected samples: neat PA4 MP, Fe and Cu-containing HMP. deconvoluted patterns are presented in Table 6 . The two crystalline reflections at $2 \theta$ values of ca. $21^{\circ}$ and $24.0^{\circ}$ are assigned to the [200] and [020] crystalline planes of the monoclinic $\alpha$-PA4 with dspacing $d_{\alpha[200]}=4.35 \AA$ and $d_{\alpha[020]}=3.71 \AA$, characterizing the interchain distance within a hydrogen-bonded sheet and the intersheet distance, respectively. As seen from Table 6 , the $\alpha$-form $d$ spacings coincide with those previously found in Ref. [29].

The diffuse scattering of the amorphous PA4 component was presented by two wide Gaussians. Notably, good fits with fitting coefficients $r^{2}>0.99$ for PA4 MP were only obtained if small amounts of a second PA4 crystalline form were considered introducing two Gaussians at angular position $2 \theta$ between $21^{\circ}$ and $22^{\circ}$. For all HMP (e.g., Fe1 and Cu1 samples in Fig. 10) these peaks had to be much stronger, adding one more reflection in the $10-15^{\circ}$ range. In similitude with the PA6 patterns deconvolutions and in accordance with the findings in Ref. [28], these reflections were assigned to $\beta[200], \beta[020]$ and $\beta[002]$ PA4 crystalline phases (the c-axis of the unit cell coincides with the chain axis). Thus, the $\beta$-PA4 coexists at room temperature with the $\alpha$-PA4 and its contribution grows whenever inorganic loads are present. For example, in the neat PA4 MP the content of the $\alpha$-polymorph is very high, the $\alpha / \beta$ ratio being greater than 11, while the presence of payloads, especially $\mathrm{Cu}$ and Fe drastically decreases the ratio to $1-2$. Apparently, these metals are strong $\beta$-nucleating agents. Similar but weaker trend was found in PA6 microparticles with metal loads [30].

Table 6 shows also that the XRD crystallinities of the PA4 MP and HMP samples are significantly higher than that estimated from solid state NMR (Table 3 ). These two techniques probe different regions of crystallinity. XRD examines the order of a crystalline phase over distances of at least $5-10 \mathrm{~nm}$ providing data on the overall crystallinity. In the solid state NMR experiment, the distance explored is not larger than $0.5-1.0 \mathrm{~nm}$ and the method gives information about local crystallinity indices based on deconvolution of signals for separate carbons. Therefore, crystallinity based on XRD measurements should be generally lower than in solid state NMR evaluations. In the present work an opposite trend is observed. The main reason for this discrepancy is probably unresolved overlapping of amorphous and crystalline NMR signals related to the two PA4 polymorphs, for which the NMR traces do not provide reliable information. Quantitative data on the coexistence of $\alpha$ - and $\beta$-PA4 is only given by the XRD deconvoluted profiles (Table 6).

\subsection{Protein adsorption study}

The newly synthesized PA4 MP and PA4 HMP samples were tested as possible carriers for protein immobilization using BSA as model protein. The experiments were carried out at $37^{\circ} \mathrm{C}$ in phosphate saline buffer at $\mathrm{pH} 7$ and $1 \mathrm{~h}$ incubation time with $10 \mathrm{mg} / \mathrm{mL}$ initial BSA concentration. It should be noted that no preliminary activation of the PA4 microparticles with aldehyde or carbodiimide compounds was applied. The results about the adsorption capacity and efficiency toward BSA are summarized in Fig. 11. Only after $1 \mathrm{~h}$ of incubation time all three tested samples displayed $>50 \%$ adsorption efficiency, which corresponds to a capacity of more than $200 \mathrm{mg}$ protein per gram of particulate substrate. Similar results were obtained recently by Cai et al. with PA6 microparticles [31] which, however, were functionalized with $\mathrm{COOH}$ groups and carbodiimide activated prior to incubation. The superior adsorption capacity of non-activated PA4 microparticles can be explained with the denser network of amide groups that enables more effective non-covalent interaction with proteins. The identity of the PA4 and protein crystalline structure mentioned above most probably additionally contributes to the better PA4-BSA affinity. 
Table 6

WAXS analysis of PA4 MP and PA4 HMP samples.

\begin{tabular}{|c|c|c|c|c|c|c|c|c|c|}
\hline Sample & $\alpha, \%$ & $\beta, \%$ & Crystal- linity, \% & $\alpha / \beta$ & $\mathrm{d}_{\alpha(200)} \AA$ & $\mathrm{d}_{\alpha(020)} \AA$ & $\mathrm{d}_{\beta(002)} \AA$ & $\mathrm{d}_{\beta(020)} \AA$ & $\mathrm{d}_{\beta(200)} \AA$ \\
\hline PA4 & 34.13 & 3.06 & 37.19 & 11.15 & 4.35 & 3.71 & - & 4.13 & 3.92 \\
\hline $\mathrm{Fe} 1$ & 24.65 & 16.61 & 41.26 & 1.48 & 4.21 & 3.62 & 6.66 & 3.99 & 3.64 \\
\hline $\mathrm{Fe}_{3} \mathrm{O}_{4} 1$ & 29.80 & 15.22 & 45.02 & 1.96 & 4.22 & 3.62 & 6.11 & 3.89 & 3.67 \\
\hline $\mathrm{Fe}(\mathrm{C}) 1$ & 26.95 & 14.12 & 41.07 & 1.91 & 4.23 & 3.61 & 6.39 & 4.16 & 3.64 \\
\hline Cu1 & 22.38 & 23.85 & 46.23 & 0.94 & 4.22 & 3.61 & 6.34 & 4.05 & 3.61 \\
\hline CNT01 & 32.25 & 12.22 & 44.47 & 2.64 & 4.22 & 3.62 & - & 3.93 & 3.75 \\
\hline
\end{tabular}

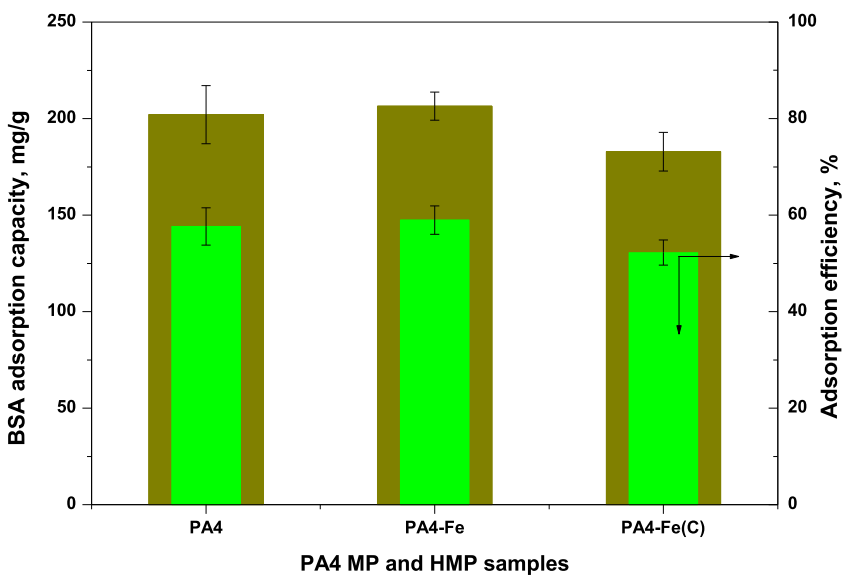

Fig. 11. Absorption capacity and absorption efficiency of selected neat PA4 and magnetic PA4 HMP toward BSA. Incubation time: $1 \mathrm{~h}$.

Leaching of iron ions from the PA4 microcapsules could be of importance in their possible biological applications. To obtain an initial qualitative idea on the leaching from the $\mathrm{Fe}_{3} \mathrm{O}_{4}$-containing microcapsules of this study, $100 \mathrm{mg}$ of the $\mathrm{Fe}_{3} \mathrm{O}_{4}-1$ sample were incubated in saline phosphate buffer $(\mathrm{pH}=7)$ for $8 \mathrm{~h}$ at $37^{\circ} \mathrm{C}$. After centrifugation, aliquot parts of the supernatant were tested for $\mathrm{Fe}^{3+}$ and $\mathrm{Fe}^{2+}$ with $\mathrm{K}_{4}\left[\mathrm{Fe}(\mathrm{CN})_{6}\right]$ and $\mathrm{K}_{3}\left[\mathrm{Fe}(\mathrm{CN})_{6}\right]$, respectively. No blue color was observed, which was interpreted as no Fe ion leaching under the conditions indicated.

Fig. 11 represents a preliminary study and is an example for the good adsorption capacity of PA4 MP and HMP. Detailed studies on this matter will be presented separately accompanied by systematic investigation of the possible leaching of metal ions under variable $\mathrm{pH}$, particles concentrations and load types.

\section{Conclusions}

Porous and semicrystalline PA4 microparticles with narrow size- and shape distributions were synthesized by activated anionic polymerization of 2-pyrrolidone. The facile and environmentally friendly one-pot process was performed at temperatures as low as $40^{\circ} \mathrm{C}$ and did not require solvents, emulsifiers or other components different than monomer, anionic initiator and imidic activator, all three of them being commercial products. Not only neat PA4 microparticles but also such carrying various magnetic and/or conductive payloads were successfully prepared and characterized. The structure and morphology of all PA4 neat and hybrid microparticles were characterized by light- and electron microscopy, FTIR, solid state NMR and X-ray diffraction techniques. Their thermal properties and crystallization behavior were studied by DSC and TGA. The preliminary study on adsorption capacity toward model protein showed up to 60\% efficiency of the magnetic PA4 hybrid particles, only after $1 \mathrm{~h}$ of incubation and without any activation or functionalization. Having in mind that the PA4 microparticles are biodegradable and biocompatible, new advanced biotechnological applications could be expected for these materials.

\section{Acknowledgements}

The authors gratefully acknowledge the financial support of the project TSSiPRO NORTE-01-0145-FEDER-000015, supported by the regional operation program NORTE2020, under the Portugal 2020 Partnership Agreement, through the European Regional Development Fund, as well as funding from FCT - Portuguese Foundation for Science and Technology within the strategic projects UID/CTM/ 50025/2013 and LA25/2013-2014. ZZD is thankful to FCT for the SFRH/BSAB/130271/2017 personal research grant.

\section{Appendix A. Supplementary data}

Supplementary data related to this article can be found at https://doi.org/10.1016/j.polymer.2018.04.080.

\section{References}

[1] W. O. Ney, Jr, W. R. Nummy, C. E. Barnes, U.S. Pat. 2,638,463, May 12, (1953)

[2] C. E. Barnes, U.S. Pat. 3,721,652, March 20, (1973).

[3] J. Roda, P. Sysel, J. Králíček, Polymerization of lactams: 47. Anionic polymerization of 2-pyrrolidone accelerated by 1-(1-pyrrolin-2-yl)-2-pyrrolidone Polym. Bull. 5 (11-12) (1981) 609-614.

[4] A. Deratani, F.J. Carrière, H. Sekiguchi, Copolymerizatíon of 2-pyrrolidone and its methyl derivatives, Thermal properties used for determination of the copolymer structure, Chem. Zvesti 30 (1976) 292-300.

[5] N. Kawasaki, A. Nakayama, N. Yamano, S. Takeda, Y. Kawata, N. Yamamoto, S. Aiba, Synthesis, thermal and mechanical properties and biodegradation of branched polyamide 4, Polymer 46 (2005) 9987-9993.

[6] N.C. Kim, J.-H. Kim, S.W. Nam, B.S. Jeon, Y.-T. Yoo, Y.J. Kim, Synthesis, thermal and mechanical properties and biodegradation of branched polyamide 4, Polymer 37 (2012) 211-217.

[7] C.E. Barnes, Nylon 4 - development and commercialization, Lenzinger Berichte 62 (1987) 62-76.

[8] R. Bacskai, Synthesis and thermal stability evaluation of end-capped nylon 4 oligomers, Polym. Bull. 11 (3) (1984) 229-236.

[9] K. Tachibana, K. Hashimoto, N. Tansho, H. Okawa, Chemical modification of chain end in nylon 4 and improvement of its thermal stability, J. Polym. Sci. Part A: Polym. Chem. 49 (11) (2011) 2495-2503.

[10] N. Kawasaki, A. Nakayama, and N. Yamano, PCT Int. Appl., WO2012161174 A1 (2012).

[11] K. Hashimoto, Ring-opening polymerization of lactams. Living anionic polymerization and its applications, Prog. Polym. Sci. 25 (10) (2000) 1411-1462.

[12] R. Puffr, J. Stehlicek, in: J.C. Salamone (Ed.), Polymeric Materials Encyclopedia, vol. 7, CRC Press Boca Raton, New York, 1996, p. 5432.

[13] N. Yamano, A. Nakayama, N. Kawasaki, N. Yamamoto, S. Aiba, Mechanism and characterization of polyamide 4 degradation by Pseudomonas sp. J. Polym. Environ. 16 (2008) 141-146.

[14] K. Tachibana, K. Hashimoto, M. Yoshikawa, H. Okawa, Isolation and characterization of microorganisms degrading nylon 4 in the composted soil, Polym. Degrad. Stabil. 95 (2010) 912-917.

[15] K. Tachibana, Y. Urano, K. Numata, Biodegradability of nylon 4 film in a marine environment, Polym. Degrad. Stabil. 98 (2013) 1847-1851.

[16] S.J. Park, E.Y. Kim, W. Noh, Y.H. Oh, H.Y. Kim, B.K. Song, K.M. Cho, S.H. Hong S.H. Lee, J. Jegal, Synthesis of nylon 4 from gamma-aminobutyrate (GABA) produced by recombinant Escherichia coli, Bioproc. Biosyst. Eng. 36 (7) (2013) $885-892$.

[17] N. Kim, J.-H. Kim, J.H. Kim, S.W. Nam, B.S. Jeon, Y.J. Kim, Preparation of Nylon 4 microspheres via heterogeneous polymerization of 2-pyrrolidone in a paraffin oil continuous phase, J. Ind. Engendering Chem. 28 (2015) 236-240.

[18] N. Dencheva, T. Nunes, M.J. Oliveira, Z. Denchev, Microfibrillar composites 
based on polyamide/polyethylene blends. 1. Structure investigations in oriented and isotropic polyamide 6, Polymer 46 (2005) 887-901.

[19] M. Szwarcz, in: Ions and Ion Pairs in Organic Reactions, vol. 2, Wiley, New York, 1974, pp. 424-426.

[20] H. Sekiguchi, B. Coutin, Polymerizability and related problems in the anionic polymerization of lactams, J. Polym. Sci. Polym. Chem. 11 (7) (1973) $1601-1614$.

[21] F. Dan, C. Vasiliu-Oprea, Anionic polymerization of caprolactam in organic media. Morphological aspects, Colloid Polym. Sci. 276 (6) (1998) 483-495.

[22] C. Vasiliu-Oprea, F. Dan, On the relation between synthesis parameters and morphology of anionic polycaproamide obtained in organic media. I. Influence of the $\mathrm{Na}\left[\mathrm{O}\left(\mathrm{CH}_{2}\right)_{2} \mathrm{OCH}_{3}\right]_{2} \mathrm{AlH}_{2}$ /isophorone diisocyanate catalytic system, J. Appl. Polym. Sci. 62 (10) (1996) 1517-1527.

[23] F. Oliveira, N. Dencheva, P. Martins, S. Lanceros-Méndez, Z. Denchev, Reactive microencapsulation of carbon allotropes in polyamide shell-core structures and their transformation in hybrid composites with tailored electrical properties, Express Polym. Lett. 10 (2016) 160-175.

[24] K. Kubo, I. Ando, T. Shiibashi, T. Yamanobe, T. Komoto, Conformations and ${ }^{13} \mathrm{C}$ NMR chemical shifts of some polyamides in the solid state as studied by highresolution 13C NMR spectroscopy, J. Polym. Sci. Part B: Polym. Phys. 29 (1) (1991) 57-66.
[25] V. Hronský, M. Koval'aková, P. Vrábel, M. Uhrínová, D. Olcák, Estimation of the degree of crystallinity of partially crystalline polypropylenes using 13C NMR, Acta Phys. Pol. A 126 (2014) 409-410.

[26] N.C. Kim, T. Kamal, S.-Y. Park, C.-G. Cho, Ji-H. Kim, Y.-T. Yoo, S.W. Nam, B.S. Jeon, Y.J. Kim, Preparation, chemical, and thermal characterization of nylon 4/6 copolymers by anionic ring opening polymerization of 2-pyrrolidone and $\varepsilon$-caprolactam, Fibers Polym. 15 (2014) 899-907.

[27] R.J. Fredericks, T.H. Doyne, R.S. Spague, Crystallographic studies of nylon 4. I. Determination of the crystal structure of the $\alpha$ polymorph of nylon 4, J. Polym. Sci. A-2 Polym. Phys. 4 (6) (1966) 899-911.

[28] R.J. Fredericks, T.H. Doyne, R.S. Spague, Crystallographic studies of nylon 4. II. On the $\beta$ and $\delta$ polymorphs of nylon 4, J. Polym. Sci. A-2 Polym. Phys. 4 (6) (1966) 913-922.

[29] M.A. Bellinger, A.J. Waddon, E.D.T. Atkins, W.J. MacKnight, Structure and morphology of nylon 4 chain-folded lamellar crystals, Macromolecules 27 (8) (1994) 2130-2135.

[30] C. Brêda, N. Dencheva, S. Lanceros-Mèndez, Z. Denchev, Preparation and properties of metal-containing polyamide hybrid composites via reactive microencapsulation, J. Math. Sci. 51 (23) (2016) 10534-10554.

[31] X. Cai, Y. Zhang, G. Wu, A novel approach to prepare $\mathrm{PA} 6 / \mathrm{Fe}_{3} \mathrm{O}_{4}$ microspheres for protein immobilization, J. Appl. Polym. Sci. 122 (4) (2011) 2271-2277. 